\title{
Package Form Code
}

National Cancer Institute

\section{Source}

National Cancer Institute. Package Form Code. NCI Thesaurus. Code C93888.

A coded value representing the state (solid, liquid, gas) and nature of the package. 